\title{
Grain Aphotic Acid Inflation Of Homely And Different Rice Genotypes In Zinc- Incomplete Clay
}

\author{
Nabi Sail \\ Department Of Science, Riphah International University Lahore, Pakistan
}

\begin{abstract}
Deficiency disease in humans living in rice growing areas is increasing speedily thanks to less absorption of mineral nutrients chelate by aphotic acid (anti-nutrients) gift in rice grains. A field study was conducted to gauge the grain aphotic acid and metal ( $\mathrm{Zn}$ ) inflation of ten field fullgrown rice (Orzo sativa L.) genotypes on a metallic element incomplete clay. each the $\mathrm{Zn}$ economical (Shua-92, IR-9, Shankar, IR-36, and IR-6) and Zn-inefficient (Sasha,. UPL-48, Khushboo-95 and RG-120) rice genotypes were enclosed within the study. 2|the 2\} metallic element treatments ( 0 and fifteen kilo ha-1) were organized in an exceedingly two issue randomized complete block style with 3 replications. $N(N)$ and phosphorus (P2O5) were applied at the speed of a hundred and twenty and eighty kilo ha-1. The rice genotypes IR-36, UPL-79, Shankar and Shua-92 were the foremost metallic element accumulators whereas; Sasha, IR-9 and Khushboo-95 the smallest amount accumulator in metallic element deficiency. metal in-efficient genotype Sasha was the best metallic element accumulator in response to metallic element application. Aphotic acid content of rice genotypes was considerably influenced ( $p$ zero.05) by the applying of metallic element fertilizer. Phosphorus concentration in rice grains attenuated with metallic element application. metal in-efficient genotypes accumulated a lot of aphotic acid in their food reserves than $\mathrm{Zn}$-efficient genotypes. Aphotic acid: metal quantitative relation attenuated considerably a lot of in metallic element-inefficient genotypes as compared to $\mathrm{Zn}$ economical genotypes, with application of metallic element fertilizer. metal economical genotype Shua-92 accumulated low concentration of aphotic acid. The rice genotypes Shua-92, IR-9, Shankar and IR-36 low accumulators of aphotic acid performed with success and contained higher concentrations of metallic element than alternative genotypes.
\end{abstract}

Keywords: substance, Rice, Genotypes, Zinc, aphotic acid 


\section{Introduction}

Micronutrient deficiency disease has affected quite three billion individuals thanks to utilizing cereal based mostly diet poor in vitamins and minerals. This world biological process and health issue is that the lacking of practical food systems that don't perpetually give nutrient wealthy foods to fulfill the biological process wants of bad individuals [1]. Food systems that nourish the globe should be modified in an exceedingly method that ensures that the provision of balanced nutrients is instantly offered to all or any individuals in adequate and reasonable amounts [2]. A property agriculture approach to scale back substance deficiency disease among those most in danger (i.e. resource-poor ladies, infants and children) is that the enrichment of main staple crops with micronutrients through plant breeding methods. the opposite approach is enhancing substances vitamin C (e.g., S-containing amino acids, etc.) that promote substance bioavailability or decreasing anti-nutrient substances (e.g. phytate, polyphenols, etc.) that inhibit bioavailability of micronutrients ar the 2 choices that would be thought-about in breeding programs [3-5].

Zinc bioavailability is considerably reduced thanks to a high intake of phytate that considerably have an effect on the absorption of metallic element within the body [9]. Phytate: metal quantitative relation of Associate in Nursing 15:1 are thought-about an index of bioavailability high, medium and low metallic element [10]. If phytate: metal quantitative relation exceeds 15:1 the absorption is low. Most agricultural crops like wheat, legumes, leaved vegetables are property and cheap supply of micronutrients for rural those that don't seem to be ready to use fruits, wealthy in trace minerals in their daily diet. Rice is most significant cereal grain when wheat in Asian country, provision shoppers with a lot of calories. Breeding of rice genotypes that contain lower concentrations of aphotic acid ar crossed with high yielding genotypes or sterilization plant genes in ways in which scale back or perhaps eliminate anti-nutrient from grains is incredibly abundant desired for increasing metallic element availableness [11].

\section{Materials and strategies}

\section{Collection of samples}

The grains of ten rice genotypes were collected when gathering of field experiment conducted at experimental farm of Nuclear Institute of Agriculture (NIA), Tandojam. The paddy was cleansed from unwanted foreign materials, like stones, dust, weeds seeds, etc. and keep at four ${ }^{\circ} \mathrm{C}$ in an 
exceedingly white goods for additional analysis. before qualitative analysis, the paddy seeds of every genotype were dried in forced draft kitchen appliance at eighty $0 \mathrm{C}$ and so processed, polished and ground in IKA FM-10 grinding mill to go through zero.5 mesh sieve. every genotype received fertilizers at the speed of a hundred and twenty kilo $\mathrm{N}$, eighty kilo phosphorus and fifteen kilo metallic element ha-1 below field conditions.

The sensitive technique of Hag and Lantzsch [13] was custom-made for the assessment of aphotic acid in rice flour samples. The sample extract (with zero. $2 \mathrm{~N} \mathrm{HCl}$ ) was heated with Associate in nursing acidic Iron III resolution of illustrious iron content. The phytate-P was measured as decrease in iron content (determined calorimetrically with two, 2bipyridine) within the supernatant. The defatted and finely ground flour samples $(0.5 \mathrm{~g})$ were extracted with ten cubic centimeter of zero. $2 \mathrm{~N} \mathrm{HCl}$ for one hour. From this extract, 0.5 cubic centimeter was taken into a stopper tubing. metallic element resolution $(1.0 \mathrm{ml})$ was more to the current and lined with the stopper. These tubes were heated in an exceedingly boiling water tub for half-hour and allowed to chill to temperature. A 2, 2, Bipyradine resolution $(2.0 \mathrm{ml})$ was more to the current and mixed. The absorbance was measured among one. 0 minute. a regular standardization curve was ready victimization identical procedure with the quality solutions of illustrious concentration of zero.0, 5.0 through thirty ppm metal phytate. victimization the quality curve the concentration of aphotic acid within the sample was calculated by the formula.

\section{Zinc Concentration}

Zinc concentration in rice grains magnified linearly with increasing metallic element application rate within the clay. The rice plants full-grown on top of things plots had lower metallic element concentrations in grains than metallic element impregnated plots, that ranged between fifteen. 4 to $21.9 \mu \mathrm{g}$ g-1The genotype "Sasha" accumulated considerably higher grain metallic element concentration (50\%) quite unfertile plots, followed by IR-9 (35\%) and Khushboo-95 (34\%), severally, with metallic element application. As anticipated, the concentrations of metallic element were abundant higher in metallic element-sensitive rice genotypes provided with fifteen kilo Zn ha-1, as compared to unfertile plots. 


\section{Phosphorus metal (P:Zn) quantitative relation}

A nutrient balance exists within the plants below traditional growth conditions and any imbalance within the concentration of nutrients could amendment their ratios. the info concerning $\mathrm{P} / \mathrm{Zn}$ ratios metallic element incomplete plants had higher $\mathrm{P} / \mathrm{Zn}$ ratios than the healthier plants. $\mathrm{P}$ : metallic element quantitative relation in metallic element incomplete plants was perpetually found to be larger than a hundred.

\section{Discussion}

As expected, the metallic element concentration was higher within the plants provided with higher metallic element fertilizer in metallic element incomplete clays, than within the plants while not metallic element fertilizer. Singh et al. [14] have steered that metallic element could also be vital for the structural and practical integrity of the basis cell plasma. These results indicated that plants plagued by metallic element fertilizer, at lower metallic element concentration, will tolerate stress for extended before important reduction of phanerogam growth occurred [15].

There are numerous reports in literature on whether or not or not a "critical" P:Zn quantitative relation exists. during this study, metallic element in-efficient rice genotypes showed the upper ratios of $P: Z n$ as compared to metallic element economical genotypes. Yield decreases occur once the P:Zn quantitative relation in tissue exceed a "critical" level. This vital level could vary between a hundred to 350 relying upon clay sort and alternative conditions. within the gift study, the P:Zn quantitative relations were well on top of this vital ratio. These results additionally showed that the $P: Z n$ quantitative relation for plants growing usually was perpetually but one hundred fifty that was the quantitative relation steered for traditional plant growth and a quantitative relation larger three hundred was indication of metallic element deficiency. The ratios of $\mathrm{P}$ and metallic element are rumored to be closely related to the presence and severity of metallic element deficiencies [16].

\section{Conclusion}

The rice genotypes Shua-92, IR-9, Shankar and IR36 low accumulators of aphotic acid and performed with success than alternative genotypes. The metallic element in-efficient genotypes Sasha and RG-120 needed supplementation of metallic element for equalization the metallic 
element concentration and absorption. metal fertilization improved metallic element standing of rice grains

\section{References}

[1] Welch RM. Biotechnology, bio fortification, and world health. Food Nutria Bull 2007.

[2] Suzanna S, Gregováb E, Sturdy E. Chemical composition and biological process quality of wheat grain. Act Chemical Slovak 2002; 2(1).

[3] Welch RM. Breeding methods for bio fortified staple plant foods to scale back substance deficiency disease globally. J Nutria 2008; 132.

[4] Overleaps D, Maher ME, Dell OBL, Kilter LD. Effects of aphotic acid on metallic element availableness in rats and artiodactyl. J Animi Sic 1999; 20: 1994.

[5] Wahhabi S, Annul FM, Butt MS, Sarkar M, Zen A. Aphotic acid content of bread ready from wheat varieties full-grown in KPK. Rashad J Agaric 2010; 20(1): 177-12.

[6] Lavender OA. Atomic number 34 In: Trace components in Human and Animal Nutrition (Ed. W. Mertz), educational Press Rolando, Everglade State 1997; pp. 312-542. 